- ACORN Australan college of | JOURNAL OF PERIOPERATIVE NURSING

Volume 31 | Issue 4

Article 2

$12-1-2018$

\title{
The impact of obesity surgery on psychosocial health
}

Follow this and additional works at: https://www.journal.acorn.org.au/jpn

Part of the Health Services Administration Commons, Health Services Research Commons, Perioperative, Operating Room and Surgical Nursing Commons, and the Surgery Commons

(c) (i)

This work is licensed under a Creative Commons Attribution 4.0 License.

\section{Recommended Citation}

Taze, Sibel; Gumuskaya, Oya; and Taşkın, Mustafa (2018) "The impact of obesity surgery on psychosocial health," Journal of Perioperative Nursing: Vol. 31 : Iss. 4 , Article 2.

Available at: https://doi.org/10.26550/2209-1092.1032

https://www.journal.acorn.org.au/jpn/vol31/iss4/2

This Article is brought to you for free and open access by Journal of Perioperative Nursing. It has been accepted for inclusion in Journal of Perioperative Nursing by an authorized editor of Journal of Perioperative Nursing. 


\section{The impact of obesity surgery on psychosocial health}

\section{Cover Page Footnote}

Dr Sibel TAZE, PhD., RN a, Oya GÜMÜŞKAYA, MSN.,RN b, Prof. Mustafa TAŞKIN, MD c a Istanbul University, Cerrahpasa Faculty of Medicine, Department of General Surgery, Director of Nursing Services. b Yeditepe University, Faculty of Health Sciences, Department of Nursing c Istanbul University, Cerrahpaşa Faculty of Medicine, Department of General Surgery, Specialist Surgeon Acknowledgments and Language We thank nurses in Istanbul University Cerrahpasa Education and Research Hospital Department of General Surgery for their support and Dylan Bradley for proofreading. Conflict of Interest Statement Writers have no conflicts of interest to declare. Statement of Informed Consent Informed and signed written consents were obtained from each participant for the study. Statement of Human and Animal Rights Ethical Committee approval was obtained before the study conducted. 


\section{Authors}

Dr Sibel Taze

PhD, RN

Istanbul University, Cerrahpasa Faculty of

Medicine, Department of General Surgery, Director of Nursing Services

Oya Gümüşkaya

MSN, RN

Yeditepe University, Faculty of Health

Sciences, Department of Nursing

Prof. Mustafa Taşkin

MD

Istanbul University, Cerrahpaşa Faculty of Medicine, Department of General Surgery, Specialist Surgeon

\section{Corresponding author}

Oya Gümüşkaya

MSN, RN

Yeditepe University, Faculty of Health

Sciences, Department of Nursing

oyagumuskaya@yahoo.com

\section{The impact of obesity surgery on psychosocial health}

\section{Abstract}

Background: As obesity affects different dimensions of health, psychosocial wellbeing of patients can be predicted to significantly improve after bariatric surgery.

Method: This qualitative study focused on determining the experience of patients who underwent bariatric surgery and the psychosocial impact of it on their daily lives and provides nurses with detailed information regarding patients' experience. While some of these outcomes were in line with the literature, they have also revealed new aspects and provided deeper understanding regarding individuals' experiences.

Results: Five themes were identified: limitations in physical activity, social isolation due to negative body image, increased self-esteem, change in romantic relations and fear of weight regain.

Conclusion: It is necessary for individuals to be supported for long-term postoperative complications, nutritional state and eating disorders. Nurses can support patients to set achievable goals and realistic expectations in order to obtain satisfactory patient results.

\section{Introduction}

Obesity is defined by the World Health Organization (WHO) as excess fat accumulation in the body to the extent that it can impair health. Obesity is a clinical and chronic disease and one of the major health problems in the world ${ }^{1,2}$. According to the WHO, 2.8 million people lose their lives every year due to obesity?. According to the OECD 2017 health statistics, 29.2 per cent of Turkish women aged 15 and over were living with obesity, while the rate is 15.3 per cent for Turkish men. This ranked the country as $11^{\text {th }}$ in the world for obesity. Due to obesity's significant impact on physical and mental wellbeing, individuals with obesity may seek methods to lose large amounts of weight rapidly, and employ radical treatments such as bariatric surgery. Initiatives for prevention of and research into the causes of obesity have also gained attention as a result of increasing severity of the issue.
Bariatric surgery has recently become the most common treatment method for obesity. In 2013, 3250 bariatric surgeries were reportedly conducted in Turkey4. Among the methods used in bariatric surgery, intestinal bypass, partial biliopancreatic bypass, gastroplasty and adjustable silicone gastric banding are the most often applied along with less invasive methods such as laparoscopic gastric banding and endoscopic gastric balloon application ${ }^{5}$. Bariatric surgery appears to be more effective due to its provision of relatively rapid and permanent weight loss in morbidly obese patients with a body mass index (BMI) of more than $40 \mathrm{~kg} / \mathrm{m}^{2}$ and are successful in alleviating the accompanying somatic diseases compared to other treatment options.

However, post-operative patient adaptation and outcomes may differ as a result of factors unrelated to the surgery ${ }^{6-8}$. As obesity is a multifaceted disease with an impact on different dimensions of health, psychosocial wellbeing of patients 
can be predicted to significantly improve after bariatric surgery following drastic weight loss in just a few months. Still, in spite of predictions for improvement in body image, studies have shown discrepancies in patient satisfaction for various reasons such as failure to meet expectations or unachievable goals ${ }^{1,9}$. It was indicated that inadequate preoperative preparation may cause psychological distress to patients in the late post-operative period regarding adaptation to the new body image or disappointment in the results ${ }^{10}$. It can be predicted that the negative psychosocial impact of the surgery may hinder early post-operative benefits, as anxiety, depression or distress will not enhance the recovery of the stomach wall or the body. For the late post-operative period, benefits attained by bariatric surgery may not be maintained due to low selfesteem in the individual.

\section{Aim}

This study focused on determining the experience of patients who underwent bariatric surgery and the psychosocial impact of it on their daily lives.

\section{Methodology}

The study was designed as qualitative, phenomenological research. The study population consisted of patients with morbid obesity who had undergone bariatric surgery in Istanbul University, Cerrahpasa Faculty of Medicine. Ethical approval was obtained from the faculty's ethical committee. The sample was determined with criteria sampling and until the data had reached the satisfactory repetitive pattern; 13 patients were included. Volunteers who had had surgery between six months and five years prior and did not have barriers to communication participated in the research.

\section{Data collection}

Individuals were approached face to face at the hospital and invited to participate. Written and verbal consent were obtained from participants individually. Confidentiality was ensured as only the researchers had access to the records, no information will be shared with third parties nor will it be used other than for this study, and participants' identities will not be published. The data was collected by the first author with one-onone, in-depth interviews using a semi-structured questionnaire that included demographic questions. Interviews took between 15 and 25 minutes. A recorder was used for the interviews. Data collection was terminated once statements were repeated or very similar (data saturation).

\section{Analysis}

The recorded materials were manually decrypted by the first two investigators. The data was read word by word to derive codes ${ }^{11}$ by first underlining the exact words from the text that appear to capture key thoughts or concepts. Preconceived themes or classification were avoided - the data slowly emerged from open ended questions such as "how would you describe that feeling?', 'what has changed in your relationship, if anything changed after the surgery?' or 'what were your thoughts back then?'. The codes appeared as 'self-confidence, felt better about myself'. The codes we have extracted were repetitive and there were not any new codes identified from the last two participants who were added to comply with a recommendation from reviewers. The three independent researchers determined the themes by conventional content analysis as the aim was to describe the psychosocial impact of bariatric surgery. After the initial analysis, categories determined by each researcher were compared and this discussion resulted in an agreement on the data saturation. The similar or meaningfully similar sub-themes were merged into the main themes; a consensus on the themes was reached by the same process afterwards.

\section{Results}

\begin{tabular}{|c|c|c|}
\hline & & $\mathrm{n}(\%)$ \\
\hline \multirow{2}{*}{ Gender } & female & $10(76.9)$ \\
\hline & male & $3(23.1)$ \\
\hline \multirow{2}{*}{$\begin{array}{l}\text { Marital } \\
\text { status }\end{array}$} & married & $9(69.2)$ \\
\hline & single & $4(30.8)$ \\
\hline \multirow{4}{*}{ Education } & primary & $3(23.1)$ \\
\hline & middle school & $2(15.3)$ \\
\hline & high school & $5(38.5)$ \\
\hline & university & $3(23.1)$ \\
\hline \multirow{2}{*}{$\begin{array}{l}\text { Family } \\
\text { history of } \\
\text { obesity }\end{array}$} & yes & 9 (69.2) \\
\hline & no & $4(30.8)$ \\
\hline Age & \multicolumn{2}{|c|}{ average $40.6(S=11.81)$} \\
\hline BMI & \multicolumn{2}{|c|}{$\begin{array}{l}\text { preoperative average } \\
45.01(S=5.64) \\
\text { post-operative average } \\
27.65(S=7.25)\end{array}$} \\
\hline
\end{tabular}

Table 1. Demographics (n:13)

$\mathrm{S}=$ standard deviation

Table 1 presents the demographics of the participants. The mean age of the participants was $40.66 \pm 11.81,69.2$ per cent were married and 69.2 per cent had a family history of obesity. The participants' BMI average was 45.01 \pm 5.64 and $27.65 \pm 7.25$ before and after the surgery respectively. High school graduates made up 38.5 per cent of the participants and 76.9 per cent were female. The average preoperative BMI was 44.33; the average post-operative BMI was 28.29. Only one out of 13 participants 
exercises regularly. Eight out of 13 participants included fibre, fresh vegetables and fruit in their diet.

Five themes were identified and grouped according to perioperative period. The themes for the preoperative period included limitations in physical activity and social isolation due to negative body image. Themes for the post-operative period included increased selfesteem, change in romantic relations and fear of weight regain.

All participants stated that they experienced various physical activity limitations related to obesity. The statements below are a few examples from the study.

'I was very sweaty, very breathless, and I was a young woman.' Participant 1 (P1)

'I was having difficulty walking, I was having trouble breathing, I was having problems walking up the stairs.' P2

‘Obesity was affecting me very much, my movements, walking up the stairs... (I) was tired when I was walking.' P3

'Physically your movements are being restricted, and you are not able to do your personal care yourself. You always have to get help ... Even when you tie your shoe laces, you are twisted, you are breathless.' P4

'I wanted to walk properly, but I could not. I needed to sit down every minute, I was getting tired quickly.' P5

'...aside from my body image, I was having a lot of difficulty while working; my feet were aching, my body was no longer able to lift the weight, I was having difficulty standing.' P6
'You cannot tie your shoe laces, you cannot wear your socks, you struggle going to the toilet... You cannot walk, you cannot do sports... was breathless climbing stairs, instead, I had used lifts only...' P8

Individuals expressed the social isolation due to negative body image, fear of loved one's reactions and discrimination. Statements are as follows:

'I did not like myself, people did not like me. You are excluded, at first you exclude yourself... I did not participate in any social activities... In your own isolation, you stand back... I spent all my free time at home, I was cleaning the house to spend time.' P1

'In social life, I was not seeing my friends as often as I used to. I was very upset when people told me that I had gained a lot of weight...' P4

'I locked myself in the house before the surgery, I did not want to see anyone...' P3

'Even when I had a job interview, I was judged differently than other people, even though I was experienced ...They thought I would not be active for the job.' P2

'You cannot just get dressed with whatever you want and go out... Towards the surgery, when I went out to a café ...I was looking for a place with the chairs that I can sit. I had difficulty.' P10

Participants emphasised that their self-esteem increased after the operation. They expressed relief when selecting clothing after the surgery, in terms of previous difficulty finding fitting and appropriate clothing for the season or the occasion in bigger sizes, which helped to build their confidence. Example statements were:
'I lost weight, gained my confidence ... going to work is easy now. I started to attract people's attention... (laughs)' P1

'Those who have not seen me for a long time were very surprised...They say 'how have you lost so much weight?'...positive reactions and it made me happy and built my confidence. I am more confident... because you are smaller...' P2

'When people lose weight, they feel better, self-confidence increases.' P4

'My friends are saying that I look a lot younger now, at least ten to fifteen years younger. ...Friends cannot recognise me...this thin. Of course this is very flattering.' P5

'I have been relieved about clothing...when I go into a large size shop, they say I should check the normal size shops. It makes me happy.' P2

'I had trouble with clothing... that has changed now, I used to be 48 in size, now I am 36 or 38... Even my foot size has changed; 42.5 it was, now it is 39.5...' P1

'I used to have a hard time finding clothes that fit. Now, when I go to a store, I do not have to worry about if I can fit into this and that...' P4

'the clothes used to pick me... now I am picking them...I had just one t-shirt and one pair of pants that would fit me and they were both black.' P13

The majority of participants have expressed the change they have experienced in romantic relationships after the surgery. The changes in participants' relationships which had existed before the operation were especially significant. Examples were: 
'I used to have a boyfriend before the surgery... People who see me now are amazed, some want to come back. It (being overweight) was not the reason for them to leave me apparently, but I think it was. ...the reactions... from opposite sex... have changed. They used to stare because I was fat, but...now they are seeing me as a lady...it is different, a woman can tell.' P2

'My partner also had the surgery 15 days after me. He says that he was attracted to me before the surgery as well, but now, he is more attracted and I told the same thing to him. (Laughs)' P3

'My partner stopped spending time outside with me... and then, after losing weight I understood that he was bothered about me being overweight. For example, when he hugs me now, I get compliments... Now I know he was distant (before the surgery)...' P4

'When I was overweight, I was 'a friend' to all men, and when I lost weight, they changed. They started to open car's doors for me, fix my seat in restaurants... My ego is satisfied, but... it does not mean anything. It's very annoying...is just superficial... 'P1

'We broke up before the surgery. He did not want me to have the surgery. I think he just wanted me to stay unwanted and left for him.. now I think back, I was with him only because I thought nobody else would want me like that...' P13

All participants expressed serious concern about regaining weight after the surgery. Examples were as follows:

'I pay attention to my food...। started to gain weight again - 61, 62, 63 and it has to stop. Actually, it might be better when I am 67...but I fear putting on weight again...' P1

'I am afraid to put on weight again, now I have a vitamin deficiency and I am about $5 \mathrm{~kg}$ under my healthy weight, I think when I am $65 \mathrm{~kg}$, it is good for my health, I definitely do not want anything above that. I am very afraid...' P2

'I'm afraid to gain weight again, so I pay attention to what I eat... I suffered so much... say 'do not dare' and I keep myself from eating.' P3

'I am afraid to gain weight again, I am very afraid. For example, when I eat a sandwich, I'm afraid. I say to myself "What if ... I continue eating and regain weight'... tell myself, today I ate this, tomorrow I should eat that.' $\mathrm{P4}$

'I'm afraid to gain weight, it was so painful...So I do everything I can to avoid weight gain.' P5

'I'm scared, I say "do not put on weight again!"' p9

\section{Discussion}

This study aimed to determine the experience of patients who underwent bariatric surgery and the psychosocial impact of the surgery on their daily lives. After consensus was reached on the material collected by in-depth interviews, five themes were determined. While some of these outcomes were in line with the literature, they also have provided deeper understanding regarding individuals' experiences, and new aspects were also revealed.

The initial theme that emerged was physical limitation. Physical limitation related to obesity creates a vicious cycle; while exercise plays an important role in the prevention of obesity, physical activity is reduced significantly by obesity. Soyuer et al. ${ }^{12}$ found in their study that college students with normal weight were more dynamic in physical activities compared to the students with obesity. It was also determined that women without obesity showed on average 24 per cent higher activity scores than the women with obesity in another study ${ }^{12}$. Aldaqal and Sehlo reported that physical functioning was significantly lower in individuals with obesity. The findings regarding physical activity are in line with the related literature; the majority of the participants stated difficulties in daily physical activity determined their decision to undergo surgery. Additionally, social pressure, fear of reaction from loved ones, judgments and discrimination prevented people with obesity from leaving their house which further limited their physical activity.

Another theme was isolation due to negative body image. Body image is also a multi-dimensional concept involving perception, attitudes and behaviours related to an individual's body and appearance ${ }^{13}$. In recent years, especially the media and Western cultures' tendency to market 'skinny' as a beauty ideal, promoting physical appearance before characteristic qualities, can cause individuals with obesity to be exposed to ever more serious discrimination and prejudice in social life $^{14,15}$. Sobal and Stunkard ${ }^{17}$ have defined the phenomenon as 'socially accepted prejudice'. People with obesity are afraid of being exposed to or have previously experienced this discrimination, as a result they isolate themselves from society ${ }^{16}$. Weineland ${ }^{19}$ and colleagues reported that social isolation was a major issue for patients with obesity. Some of the patients in the study stated that they preferred not to spend much time outside of their house when they were overweight. This 
result was predicted and points out the extent of the social trauma, the fear of humiliation and the exclusion that they experience. The social isolation also prevents, or at least discourages, them from participating in physical activities. Therefore people with obesity spend more time alone which can contribute to their unhealthy eating behaviour.

As expected, many studies indicate that individuals who underwent bariatric surgery had higher scores for body image, quality of life and self-esteem ${ }^{2,17}$.It was also reported that as the $\mathrm{BMI}$ increases, the self-esteem score decreases in individuals ${ }^{14}$. Additionally, a meta-analysis study revealed that the dissatisfaction rate for body image of individuals with obesity was significantly higher ${ }^{13,18}$. Moreover, individuals with obesity express difficulties with dressing appropriately to the season and social occasion, and that not being able to find the right size clothes increases the problem of their negative body image. Individuals express positive feelings as they approach the body shape they would like to have after the surgery ${ }^{19}$. In the study, the participants stated that as they lose weight, they can get smaller size clothes, so it is easier to find suitable clothing, they feel happier as a result of the availability of clothing and these positive emotions can increase positive body image as it gives confidence. Participants in the study expressed an increase in their confidence after they had lost weight and the surgery affected their body image favourably. As this result was consistent with previous studies, it is undeniable that weight loss affects body image positively which builds self-esteem.

While the majority of individuals in the study expressed positive changes in romantic relationships, some participants stated that this difference was superficial. It was determined that while there was an expectation for romantic relationships to improve after weight loss, parallel to improved body image and self-esteem, there was no change found in the sexual life and partner relations of the individuals in the long-term studies ${ }^{20}$. The changes regarding romantic relationships can be difficult to measure and are highly individual; therefore, this concept will be left to readers' judgement and more research needs to be conducted in the matter. The study revealed that the participants with the same partners were happier in their relationship after the surgery, while some of them expressed this change as a neutral or negative experience, in their words 'flattering but superficial'.

In the literature, it is stated that after bariatric surgery the excessive eating habits of the preoperative period are reduced, as the capacity of the stomach only allows eating small portions. In the long term, patients are expected to maintain normal eating habits. However, eating disorders may continue to distress the patients psychologically after the surgery. They may exercise strict diets on the basis of constant fear of weight regain ${ }^{21}$. In the study, the individuals have expressed a great deal of fear regarding regaining weight and 'going through the same struggles they had experienced in the preoperative period'. Patients' distress may cause eating disorders or other psychological issues and it is a concern for their psychosocial wellbeing as much as their physical health status. For example, some participant's statements regarding vitamin deficiency and being five to six kilograms under the healthy weight indicates that individuals need psychological support and nutritional guidance after the operation. Moreover, the statement of eight out of ten participants regarding the absence of regular exercise underlined the need for post-operative support and education. Additionally, it may be presumed by these findings that the patients felt as if they had no control over their weight management.

\section{Limitations of the study}

The study was conducted as qualitative, therefore large samples are both inappropriate and physically impossible for in-depth interview analysis. Additionally, semistructured questions were limited to demographics, weight loss, exercise status and psychosocial impacts of the surgery.

\section{Conclusion}

It was observed that obesity has negative impacts on individuals in many aspects of their health. Bariatric surgery, which has been widely used in recent years, seems to increase the quality of life and improve health physically and psychologically in the relative short term. On the other hand, it may be necessary for individuals to be supported to avoid long term postoperative complications related to nutritional state and eating disorders. Nurses can provide support to patients to set achievable goals and realistic expectations.

Above all, raising awareness of and working on issues such as adequate nutrition, physical activity, psychological health and eating disorders should be the primary goal of governments and health workers to prevent obesity which is becoming increasingly endemic in the world. 


\section{References}

1. Ribeiro GA, Giampietro HB, Barbieri LB, Pacheco RG, Queiroz R, Ceneviva R. Body perception and bariatric surgery: The ideal and the possible. Arq Bras Cir Dig 2013;26(2):124-128. doi:10.1590/S010267202013000200011.

2. Aldaqal SM, Sehlo MG. Depression and self esteem in patients with morbid obesity: The effect of sleeve gastrectomy. J Am Sci 2011;7(12):1116-1123.

3. World Health Organization (WHO). Global Health Observatory (GHO) data. Overweight and obesity. Geneva: WHO; 2017 [cited 2018 January 16]. Available from: www.who.int/ gho/ncd/risk_factors/overweight_obesity/ obesity_adults/en/.

4. Angrisani L, Santonicola A, Iovino P, Formisano G, Buchwald H, Scopinaro N. Bariatric surgery worldwide 2013 Obes Surg 2015;25(10):1822-1832. doi:10.1007/s11695-0151657-z.

5. Tam AA, Çakır B. Approach of obesity in primary health care. Ankara Med J 2012;12(1):37-41.

6. Abilés V, Rodríguez-Ruiz S, Abilés J, Obispo A, Gandara N, Luna Vet al. Effectiveness of cognitive-behavioral therapy in morbidly obese candidates for bariatric surgery with and without binge eating disorder. Nutr Hosp 2013;28(5):1523-1529. doi:10.3305/ nh.2013.28.5.6699.

7. Gilmartin J, Long AF, Soldin M. Changing body image and well-being: Following the experience of massive weight loss and body contouring surgery. Healthcare (Basel) 2014;2(2):150-165. doi:10.3390/ healthcare2020150.

8. Pataky Z, Carrard I, Golay A. Psychological factors and weight loss in bariatric surgery. Curr Opin Gastroenterol 2011;27(2):167-173. doi:10.1097/MOG.0b013e3283422482.
9. Neil JA. Perioperative nursing care of the patient undergoing bariatric revision surgery. AORN J 2013;97(2):210-229. doi:10.1016/AORN J 2012.11.013.

10. Faccio E, Nardin A, Cipolletta S. Becoming ex-obese: Narrations about identity changes before and after the experience of the bariatric surgery. J Clin Nurs 2016;25(1112):1713-1720. doi:10.1111/jocn.13222.

11. Hsieh H-F, Shannon SE. Three approaches to qualitative content analysis. Qual Health Res 2005;15(9):1277-1289. doi:10.1177/1049732305276687.

12. Soyuer F, Ünalan D, Elmalı F. Physical activity in normal weight and obese university students. J Int Hum Sci 2010;7(2):862-872. Available from: www.acarindex.com/ dosyalar/makale/acarindex-1423936563.pdf.

13. Wilms B, Ernst B, Thurnheer M, Schultes B. Subjective and objective physical activity patterns after Roux-en Y gastric bypass surgery compared with non-operated obese and non-obese control women. Obes Res Clin Pract 2016;10(1):49-55. doi:10.1016/j. orcp.2015.02.010.

14. Weinberger NA, Kersting A, Riedel-Heller SG, Luck-Sikorski C. Body dissatisfaction in individuals with obesity compared to normal-weight individuals: A systematic review and meta-analysis. Obes Facts 2017;9(6):424-441. doi:10.1159/000454837.

15. Sharma B, Mahajan H, R. Suryawanshi S, Bhondve A. Assessment of co-morbidities and self esteem in obese population of urban slum of Mumbai. Int J Prev Treat 2013;1(4):61-66. doi:10.5923/j.ijpt.20120104.02.

16. Ehlert C, Marston R, Fontana F, Waldron J. Weight bias in schools and how physical educators can assist in its demise. Physical Educator 2015;72(3):403-12.

17. Sobal J, Stunkard AJ. Socioeconomic status and obesity: A review of the literature. Psychol Bull 1989;105(2):260-275.
18. Tezcan B, Kurt E. Obez bireylerde benlik saygisi, beden algisi ve travmatik geçmiş yaşantilar. Istanbul: Government of Turkey; 2009 [cited 2018 January 9]. Available from: www.istanbulsaglik.gov.tr/w/tez/pdf/ psikiyatri/dr_bahar_tezcan.pdf.

19. Weineland S, Arvidsson D, Kakoulidis TP, Dahl J. Acceptance and commitment therapy for bariatric surgery patients, a pilot RCT. Obes Res Clin Pract 2012;6(1):e-e90. doi:10.1016/j.orcp.2011.04.004.

20. Sarwer DB, Wadden TA, Moore RH, Eisenberg MH, Raper SE, Williams NN. Changes in quality of life and body image after gastric bypass surgery. Surg Obes Relat Dis 2010;6(6):608-614. doi:10.1016/j. soard.2010.07.015.

21. Versteegden DP, Van Himbeeck MJ, Nienhuijs SW. Improvement in quality of life after bariatric surgery: Sleeve versus bypass. Surg Obes Relat Dis 2018;14(2):170-174. doi:10.1016/j.soard.2017.10.008.

22. Jumbe S, Bartlett C, Jumbe SL, Meyrick J. The effectiveness of bariatric surgery on long term psychosocial quality of life - a systematic review. Obes Res Clin Pract 2016;10(3):225-242. doi:10.1016/j. orcp.2015.11.009.

23. Vangoitsenhoven R, Frederiks P, Gijbels B, Lannoo M, Van der Borght W, Van den Eynde A et al. Long-term effects of gastric bypass surgery on psychosocial well-being and eating behavior: Not all that glitters is gold. Acta Clin Belg 2016;71(6):395-402. doi:10.1080 /17843286.2016.1174393.

24. Kubik JF, Gill RS, Laffin M, Karmali S. The impact of bariatric surgery on psychological health. J Obes 2013;2013:837989. doi:10.1155/2013/837989. 